\title{
3D Visualizations of Land Cover Maps
}

\author{
Oscar Rosario Belfiore ${ }^{1}$, Pamela D’Allestro ${ }^{1}$, Claudio Meneghini ${ }^{1}$, \\ Claudio Parente ${ }^{1}$ \\ '(Department of Sciences and Technologies/ University of Naples “Parthenope”, Italy)
}

\begin{abstract}
Land Cover maps supply information about the physical material at the surface of the Earth (i.e. grass, trees, bare ground, asphalt, water, etc.). Usually they are $2 D$ representations so to present variability of land covers about latitude and longitude or other type of earth coordinates. Possibility to link this variability to the terrain elevation is very useful because it permits to investigate probable correlations between the type of physical material at the surface and the relief. This paper is aimed to describe the approach to be followed to obtain 3D visualizations of land cover maps in GIS (Geographic Information System) environment. Particularly Corine Land Cover vector files concerning Campania Region (Italy) are considered: transformed raster files are overlapped to DEM (Digital Elevation Model) with adequate resolution and $3 D$ visualizations of them are obtained using GIS tool. The resulting models are discussed in terms of their possible use to support scientific studies on Campania Land Cover.
\end{abstract}

Keywords: $3 D$ visualization, Land Cover Map, GIS, DEM

\section{Introduction}

The history of computer visualization goes back several decades, but its importance has grown more significantly in recent years [1]. Its beginnings are marked in 1970s and the early 1980s by the introduction and progress of Computer Aided Design (CAD) systems. In 1987 McCormick et al. formally used the term 'visualization' to indicate a method of computing that gives visual form to complex data: they remark as the ability to visualize complex computations and simulations is fundamental to ensure the integrity of analyses, to provoke insights, and to transfer those insights to others [2]. Current visualization technology has spun off from developments in the motion picture industry, the military, the automotive and the aerospace industries [3].

In a context of geographic visualization more approaches can be identified. Haklay in 2002 classifies five possibilities: 1) Traditional two-dimensional maps; 2) Perspective view or 2.5D representation that uses the laws of perspective to give the viewer the feeling of distance and depth; 3 ) a sequence of $2.5 \mathrm{D}$ representations to create an animated movie; 4) A $2.5 \mathrm{D} / 3 \mathrm{D}$ interactive environment where the user can control the way to see the representation on a flat screen without any special-purpose devices; 5) An immersive 3D environment based on the use of devices that enable this kind of immersion i.e. Head Mounted Displays (HMD) [4].

2.5/3D visualization can be used in geoscience applications to show both spatial and thematic information. Data concerning the relief configuration in terms of height variability in relation to sea level or another reference surface (i.e. earth ellipsoid) can be processing using an interpolation algorithm so to generate a Digital Elevation Model (DEM). 2D thematic maps showing the spatial distribution of phenomena (i.e. land cover, pollution, population density, etc.) in a geographic area can be draped on DEM of the same scene so to link the theme also to the heights and display it in 3D. In other terms, the integration of thematic layers and DEM permit to display contextually the variability of both the morphology and territorial and / or environmental components [5]. The use of appropriate textures and 3D object libraries permits to obtain realistic models [6]. This paper is aimed to remark two aspects of the 3D visualization applied to Land cover maps: the possibilities to investigate the physical materials at the surface of the earth in relation to the terrain morphology; the ease to transform 2D land cover models in 3D ones using GIS tools. To achieve this objective CORINE Land Cover maps concerning Campania (Italy) are used to be draped on DEM with $20 \mathrm{~m}$ cell size. The paper is organized as follows. Section 2 describes the data and methods: short descriptions of the study area, typical characteristics of the CLC data and adopted methodological approach based on ArcGIS 10.3 software are reported. Section 3 presents and discusses the results. Finally, Section 4 draws some conclusions.

\section{Data And Methods}

The study area

Located in Southern Italy, Campania has an area of $13,590 \mathrm{~km}^{2}$ and a coastline of $350 \mathrm{~km}$ on the Tyrrhenian Sea. The region includes three gulfs (Naples, Salerno and Policastro) as well as three islands (Capri, Ischia and Procida). Campania presents two costal lowlands, one north of Naples (the Volturn river basin and the Terra di lavoro), the other south of Salerno (the plain of the lower Sele river), that are separated by the volcanic regions named Campi Flegrei and Vesuvius $(1,277 \mathrm{~m})$ and the Lattari mountains with San Michele 
$(1,444 \mathrm{~m})$. The interior areas are hilly and mountainous with several massifs, i.e. Taburno $(1,344 \mathrm{~m})$, Partenio $(1,573 \mathrm{~m})$, Matese (Gallinola, $1,923 \mathrm{~m})$. The region is mostly hilly $(50.8 \%)$, in part mountainous $(34.6 \%)$ and flat (14.6\%). Campania is the third-most-populous region of Italy, with 5,850,850 inhabitants at the end of 2015. Considering its total area, it is the most densely populated region in the country [7].

\section{CORINE Land Cover data}

CORINE means "coordination of information on the environment" and it indicates the European program initiated in 1985 and still working on many different environmental issues. The Corine databases are produced by the European Environment Agency (EEA) and one of these named CORINE Land Cover (CLC) is an inventory of land cover in 44 classes. CLC is operationally available for most areas of Europe and presented as a cartographic product, at a scale of 1:100,000. This database uses a Minimum Mapping Unit (MMU) of 25 hectares (ha) for areal phenomena and a minimum width of $100 \mathrm{~m}$ for linear phenomena. The time series are complemented by change layers, which highlight changes in land cover with an MMU of 5 ha. The inventory was initiated in 1985 (reference year 1990) and updates were produced in 2000, 2006, and 2012 [8].The first level includes the main categories of the land cover/land use (5 classes: artificial areas, agricultural land, forests and seminatural areas, wetlands, water surfaces). The second level covers physical and physiognomic entities at a higher level of detail ( 15 classes: urban zones, lakes, forests, etc). The third level is composed of 44 classes [9].CLC was elaborated based on the visual interpretation of satellite images (SPOT, LANDSAT TM and MSS). To enhance interpretation and allocate the areas into the categories of the CORINE Land Cover auxiliary data (aerial photographs, topographic or vegetation maps, statistics, local knowledge) were used [10]. For the application described in this paper CLC data in vector format (shape file) concerning Campania Region were used. They were extracted from CLC 2000 available online at SINANET website [11] using the software ArcGIS 10.3 by ESRI. In figure 1, level 1 of the extracted dataset is mapped.

\section{DEM}

A Digital Elevation Model (DEM) permits to represent topographic surface of the bare earth [12]. The files contain the spatial elevation data of the terrain as a rectangular grid [13]. Only the terrain relief is represented because trees, shrubs, buildings and other artificial features (i.e. bridges, dams, etc.) are omitted. Generally, data are stored as an equal-spaced grid model in Cartesian coordinate system (x, y, z) or in geographic coordinate system (angular coordinates of latitude and longitude). Elevation can be visualized as a grey-scale plot, but this image is unable to represent subtle variations in topography, so Geographic software packages visualize them in 3D using several different techniques [14].For this application, DEM by IGM (Istituto Geografico Militare) concerning Campania, georeferred in UTM - WGS 84 plane coordinates - Zone $33 \mathrm{~N}$ and with $20 \mathrm{~m}$ cell size, was used.

\section{Drape}

Drape can be defined as a perspective or panoramic rendering of a two-dimensional image superimposed onto a three-dimensional surface; for example, an aerial photograph might be draped over a DEM to create a realistic terrain visualization [15]. Viewing 2D-images draped over a terrain surface helps to better understand the images and how they relate to the shape of the earth [16]. Photorealistic terrain visualization can be obtained integrating information about terrain color (texture) and topography: the DEM resolution may be less than that of the texture, a typical ration between resolutions being 1:5 [17]. Illumination use permits to achieve realistic effects: sun lighting applies shading to the surfaces of the 3D shape. The sun position can be usually set by the operators in terms of two angles, the azimuth (the angle measured from north in clockwise degrees from $0^{\circ}$ to $360^{\circ}$, so to define in which direction the Sun is) and the elevation (the angle between the horizon and the centre of the Sun's disc). Vertical exaggeration [18] can be introduced to enhance the elevation: in areas with flat topography, it may be advantageous to exaggerate the surface to highlight the subtle physical features that are there. For this application, the primary vector CLC data were converted into raster format with cell size $20 \mathrm{~m}$ using ArcGIS: three tiff files were produced, one for each level. The resulting files were draped on IGM DEM using ArcScene, a 3D viewing application for GIS data included in ArcGIS. 


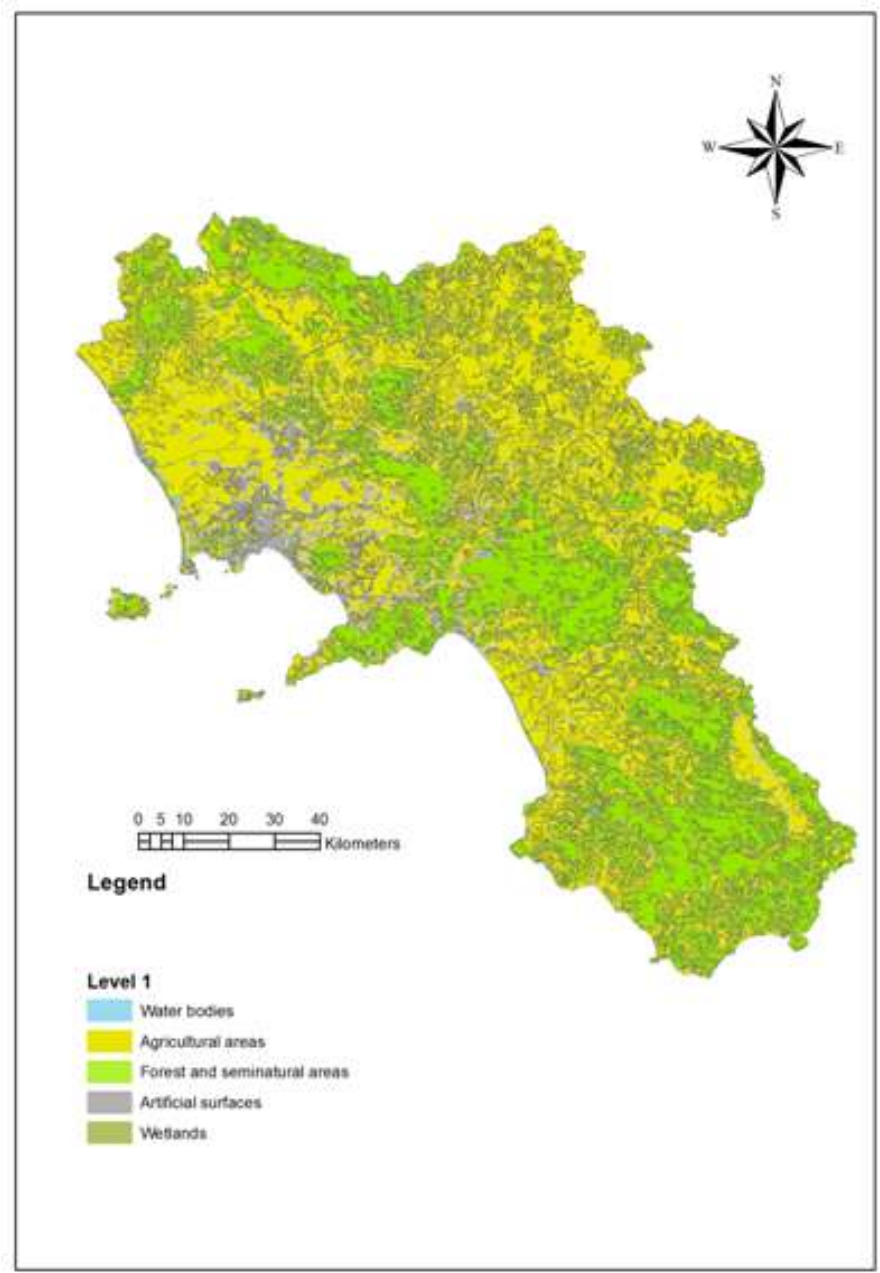

Figure 1: CLC 2D map of Campania (Italy) - Level 1

\section{Results And Discussion}

In the next two figures, 3D visualizations of the CLC Campania data are reported. Particularly, fig. 2 concerns 3D visualization of the CLC Level 1 for the entire region: it remarks as the most part of the artificial surfaces is located in the plane zones while forest and seminatural areas are generally positioned in the hilly and mountainous zones; agricultural areas involve both plane and hilly zones, but are very limited in mountainous zones. In Fig. 3 more details about CLC Level 2 of the Vesuvius are shown, using Vertical exaggeration $=2$ : it is evident that the vegetation becomes ever sparser with the increase of the elevation; forests give way to scrub and/or herbaceous vegetation associations, while open spaces with little or no vegetation are at the top.

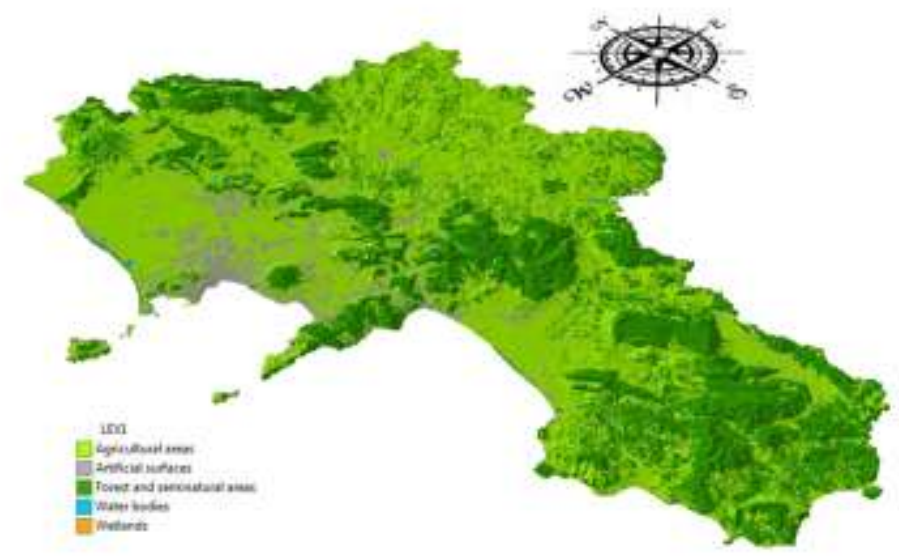

Figure 2: 3D visualization of CLC 2D map of Campania (Italy) - Level 1 

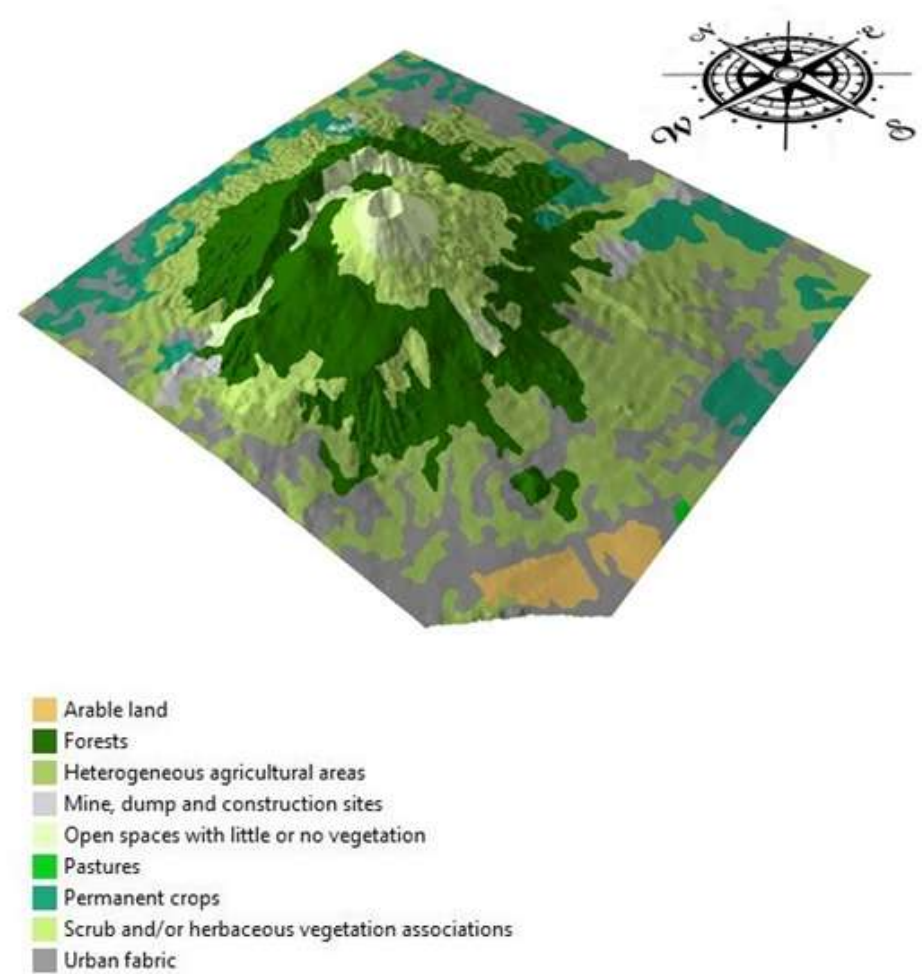

Figure 3: 3D visualization of CLC 2D map of Vesuvius area - Level $2($ Vertical exaggeration $=2)$

\section{Conclusion}

This paper demonstrates as 3D visualization can be advantageous and easily applied to land cover maps. Particularly, two aspects are remarked: the opportunity to investigate the variability and distribution of the physical materials at the surface of the Earth in relation to the terrain morphology; the simplicity to obtain 3D visualization of traditional 2D land cover maps using GIS tools. ArcGIS software and its 3D viewing (ArcScene) can support the complete procedure to obtain 3D visualization of land cover maps. The application on CLC 2000 data (levels 1, 2, 3) concerning Campania can usefully support studies on this region permitting to see simultaneously terrain shape and land cover richness. Using the same resolution $(20 \mathrm{~m})$ for both DEM and CLC raster maps, it is possible to see clearly the land cover 3D models without loss of detail neither for morphology, nor for the thematic layer.

\section{Acknowledgements}

This paper illustrates results of research activities carried out at Laboratory of Geomatics, Remote Sensing and GIS, Department of Sciences and Technologies (DiST) - University of Naples "Parthenope". We would like to thank Prof. Raffaele Santamaria, the Director of the DiST, for his scientific support of our research activities.

\section{References}

[1] P. Mileff, K. Nehéz, K., and J. Dudra, Accelerated Half-Space Triangle Rasterization, Acta Polytechnica Hungarica, 12(7), 2015, 217-236.

[2] B. H. McCormick, T. A. De Fanti, and M. D. Brown, Visualization in scientific computing, IEEE Computer Graphics and Applications, 7(10), 1987, 69-69.

[3] P. R. Thota, 3D Visualization of Highway Corridors: The I-77/81 Case Study near Wytheville, doctoral diss., Virginia Polytechnic Institute and State University, 2002.

[4] M. E. Haklay, Virtual reality and GIS: Applications, trends and directions, in P. Fisher, and D. Unwin, Virtual Reality in Geography, 5 (New York: Taylor \& Francis, 2002) 47-57.

[5] P. Maglione, C. Parente, R. Santamaria, and A. Vallario, Modelli tematici 3D della copertura del suolo a partire da DTM e immagini telerilevate ad alta risoluzione WorldView-2, Rendiconti Online della Società Geologica Italiana, 30, 2014, 33-40.

[6] R. Wack, and H. Stelzl, Laser DTM generation for South-Tyrol and 3D-visualization, International Archives of Photogrammetry, Remote Sensing and Spatial Information Science, 36, 2005, 3-W19, 48-53.

[7] ISTAT. Popolazione residente al $1^{\circ}$ gennaio 2015, Dati Istat, Available at: http://dati.istat.it/ Index.aspx? DataSet Code=DCIS_POPRES1

[8] Copernicus Programme, CORINE Land Cover, Copernicus Global Land service web site, available at: http://land.copernicus. eu/pan-european/corine-land-cover

[9] European Environment Agency (EEA), Corine Land Cover map, EEA, Copenhagen, 2012.

[10] European Environment Agency (EEA), Agricultural Areas in Europe, EEA, Copenhagen, 2012. 
[11] ISPRA, SINANET - Rete del Sistema Informativo Nazionale Ambientale, available at: http://www.sinanet.isprambiente.it/it

[12] J. P. Wilson, Digital terrain modeling, Geomorphology, 137(1), 2012, 107-121.

[13] P. A. Burrough, and R. A. McDonnell, Principles of Geographic Information Systems (Oxford University Press: Oxford, 1998).

[14] M. J. Smith, and C. D. Clark, Methods for the visualization of digital elevation models for landform mapping. Earth Surface Processes and Landforms, 30(7), 2005, 885-900.

[15] ESRI. Drape, Esri support GIS dictionary, Available at http://support.esri.com/other-resources/gis-dictionary

[16] SEOS, 3d Models, in SEOS, Science Education through Earth Observation for High Schools, available at: http://www.seosproject.eu/modules/3d-models/3d-models-c03-p04.html

[17] D. Cohen, and C. Gotsman. Photorealistic terrain imaging and flight simulation. Comput. Graphics Applications, 145, 1994, 10-12.

[18] G. F. Jenks, and F. C. Caspall. Vertical exaggeration in three-dimensional mapping. Technical Report, 1967, Kansas Univ. Lawrence Dept. of Geography. . 